\title{
Kinetics Study of Palm Fatty Acid Distillate Esterification with Glycerol over Strong Acidic Cation Exchanger Tulsion 42SM
}

\author{
Hanifrahmawan Sudibyo $^{\mathrm{a}, *}$, Rochmadi $^{\mathrm{b}}$, and Mohammad Fahrurrozi ${ }^{\mathrm{c}}$ \\ Chemical Engineering Department, Gadjah Mada University, Jalan Grafika No.2 Sleman, Yogyakarta, \\ Indonesia 55281 \\ Email: ahanifrahmawan.s@mail.ugm.ac.id (Corresponding auhtor), brochmadi@ugm.ac.id, \\ cmfrozi@chemeng.ugm.ac.id
}

\begin{abstract}
Palm Fatty Acid Distillate (PFAD) is a byproduct of CPO production. PFAD conversion into monoglyceride would give significant economic added value to it. With free fatty acid as the major component which composes the PFAD, then the esterification process was the right choice. Utilization of strong acidic cation resin as a catalyst is interesting. The catalyst could be easily separated physically. Natural esterification reaction would run reversibly so that the reflux system would be created to remove water. Reflux system used xylene as the solvent. To find the optimum condition for reaction parameters, reaction temperature, mole ratio of PFAD-glycerol, and catalyst loading were varied. Two heterogeneous reaction mechanisms, Langmuir-Hinshelwood and Eley-Rideal model, were tried to fit with the experimental data which resulted in the first model fitted the experimental data better than the second model. The reaction mechanism would involve the side reaction of diglyceride and triglyceride formation.
\end{abstract}

Keywords: Palm fatty acid distillate, Langmuir-Hinshelwood, Eley-Rideal, cation resin, esterification, reflux system.

ENGINEERING JOURNAL Volume 21 Issue 1

Received 23 March 2016

Accepted 4 July 2016

Published 31 January 2017

Online at http://www.engj.org/

DOI:10.4186/ej.2017.21.1.45 


\section{Introduction}

Huge interest of industrial sector to the utilization of bio-based raw material in chemical process is related to the degradable and renewable characteristics of the material. Palm Fatty Acid Distillate (PFAD), a biobased raw material, is a byproduct of Crude Palm Oil (CPO) production. For every one hundred tons CPO produced, there would be 3.66 tons of PFAD produced [1]. Indonesia domestic production of $\mathrm{CPO}$ reached thirty one millions metric ton in 2014. PFAD is very promising to be converted into monoglyceride in only one step, i.e. esterification. Triglyceride, the major component of CPO, could be transesterified with glycerol to produce monoglyceride [2].

The esterification of PFAD-glycerol provided choices for the reaction catalysts. Strong acid catalysts application in industry such as $\mathrm{H}_{2} \mathrm{SO}_{4}$, p-TSA, and Lewis acid were hindered by environmental aspect because of its complex separation process [3]. To make the separation process easier, the catalyst must be insoluble or heterogeneous so that it only requires the physical separation process. In this research, the esterification reaction used strong acidic cation exchanger resin as a catalyst.

Monoglyceride has two unreacted hydroxyls, which enable modification of hydroxyls into other derivative products from monoglyceride, such as alkyd resin. The synthesis of alkyd resin required that a reaction occur between monoglyceride and polyacid such as maleic anhydride, phtalic anhydride, and maleic acid [4]. The process is then called two-step process because PFAD is converted firstly into monoglyceride before reacting with polyacid to form alkyd resin. The more monoglyceride produced rather than di- and tri-glyceride, the better the derivative product characteristic can be created. The ideal type of monoglyceride used in this process is 2-monoglyceride (secondary mono ester of glycerol). When it reacts with polyacid, such as phtalic anhydride or maleic anhydride, it forms well-ordered linear chain of alkyd resin. Therefore, this research studied the influence of strong acidic cation exchanger as solid catalyst, reaction temperature, and mole ratio of PFAD-glycerol upon the reaction product, by modelling the reaction mechanism of PFAD-glycerol esterification. The reaction product was then analyzed to know the composition of mono-, di-, and tri-glyceride since the possibility of diglyceride and triglyceride formation from PFAD esterification was opened [5].

One possible mechanism to describe heterogeneous esterification reaction is Eley-Rideal [6, 7]. EleyRideal mechanism considered that only glycerol be adsorbed on the catalyst because of its polarity. The reaction between adsorbed glycerol and PFAD occurs in the bulk liquid. The main reaction produced monoglyceride and the two side reactions produced diglyceride and triglyceride [8]. Water as the side product is formed in the bulk liquid so that only mono-, di-, and tri-glyceride need to be desorbed from the catalyst. The reaction mechanism is illustrated in Fig. 1(a). From the reaction mechanism, the rate of reaction equation can be constructed by assuming that the two side reactions take roles and surface reaction is the rate-limiting. The equations are below:

a. Monoglyceride formation:

$$
r_{M}=k_{r 1} \cdot C_{p} \cdot C_{G} \cdot \frac{1}{\left(1+K_{1} \cdot C_{G}+K_{5} \cdot C_{M}+K_{6} \cdot C_{D}+K_{7} \cdot C_{T}\right)}
$$

b. Diglyceride formation:

$$
r_{D}=k_{r 2} \cdot C_{p} \cdot C_{M} \cdot \frac{1}{\left(1+K_{1} \cdot C_{G}+K_{5} \cdot C_{M}+K_{6} \cdot C_{D}+K_{7} \cdot C_{T}\right)}
$$

c. Triglyceride formation:

$$
r_{T}=k_{r 3} \cdot C_{p} \cdot C_{D} \cdot \frac{1}{\left(1+K_{1} \cdot C_{G}+K_{5} \cdot C_{M}+K_{6} \cdot C_{D}+K_{7} \cdot C_{T}\right)}
$$

Another possible mechanism to describe heterogeneous esterification reaction is Langmuir Hinshelwood [9]. Both PFAD and glycerol will be adsorbed. Although PFAD is actually non-polar, the carboxylic group at the end of the carbon chain enables it to be adsorbed by the catalyst. Glycerol is obviously adsorbed because of its polarity. The reaction mechanism is illustrated in Fig. 1(b). Based on the reaction mechanism, the rate of reaction equation can be written as follow, by assuming that the two side reactions take roles and surface reaction is the rate-limiting. 
a. Monoglyceride formation:

$$
\left.r_{M}=k_{r 1} \cdot C_{p} \cdot C_{G} \cdot\left(\frac{1}{\left(1+K_{1} \cdot C_{p}+K_{2} \cdot C_{G}+K_{9} \cdot C_{M}+K_{10} \cdot C_{D}+K_{11} \cdot C_{T}+K_{A} \cdot C_{A}\right.}\right)\right)^{2}
$$

b. Diglyceride formation:

$$
r_{D}=k_{r 2} \cdot C_{p} \cdot C_{G} \cdot\left(\frac{1}{\left(1+K_{1} \cdot C_{p}+K_{2} \cdot C_{G}+K_{9} \cdot C_{M}+K_{10} \cdot C_{D}+K_{11} \cdot C_{T}+K_{A} \cdot C_{A}\right)}\right)^{2}
$$

c. Triglyceride formation:

$$
r_{T}=k_{r 3} \cdot C_{p} \cdot C_{G} \cdot\left(\frac{1}{\left(1+K_{1} \cdot C_{p}+K_{2} \cdot C_{G}+K_{9} \cdot C_{M}+K_{10} \cdot C_{D}+K_{11} \cdot C_{T}+K_{A} \cdot C_{A}\right)}\right)^{2}
$$

Based on these equations, simultaneous ordinary differential equations can be derived from unsteady state mass balance of each component. These differential equations are solved numerically, and the corresponding reaction rate constants can be determined by minimizing the Sum of Square of Error (SSE) between calculated and experimental data of unreacted $-\mathrm{COOH}$ concentration.

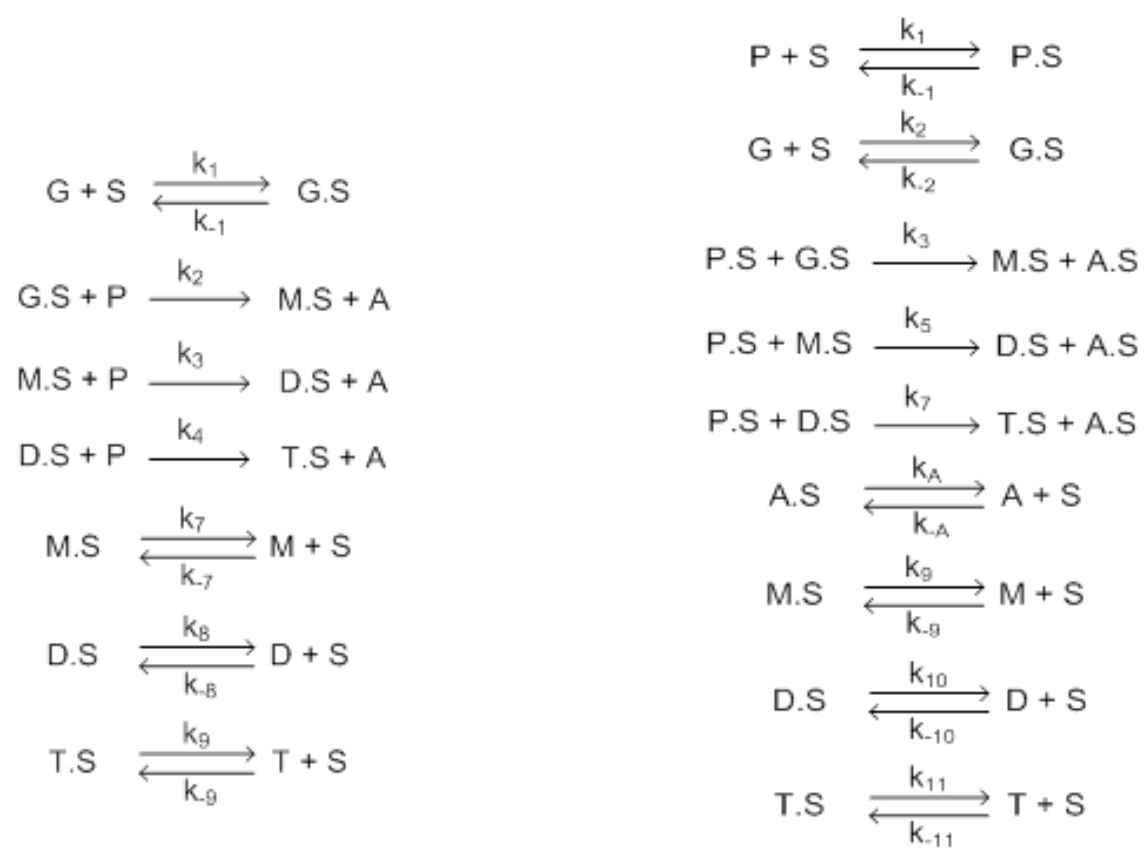

(a)

(b)

Fig. 1. Reaction mechanism for (a) Eley-Rideal and (b) Langmuir-Hinshelwood model.

\section{Experimental}

\subsection{Materials}

PFAD supplied by PT. Alkindo Mitrajaya had an acid number of $135.22 \mathrm{mg} \mathrm{NaOH} . \mathrm{g}^{-1}$. Technical grade glycerol had purity of $78.94 \% \mathrm{w} / \mathrm{w}$. Other chemicals used in this research were xylene, ethanol $96 \%$, sodium hydroxide (Merck), periodic acid (Merck), and sulfuric acid 98\% (Merck). Xylene was used to 
remove water from reaction mixture through reflux system. Tulsion $42 \mathrm{SM}$ was used as a catalyst, presented cation exchange capacity of 3.60 meq.g- ${ }^{-1}$ equivalent with 1.93 eq.L $\mathrm{L}^{-1}$. All standards consisting of monoglycerides, diglycerides, triglycerides, palmitic acid, stearic acid, oleic acid, and linoleic acid were supplied by Fluka. For composition analysis, TLC alumina plate was used, and mobile phase solution consisted of n-hexane, ethyl ether, and methanol (analytical grade), chloroform (Merck).

\subsection{Esterification Procedure}

The esterification reaction of PFAD and glycerol were carried out in the three-necked-flask of $500 \mathrm{~mL}$ capacity fitted with reflux condenser, a thermometer, and a stirrer. PFAD, xylene, and catalyst were charged into the reactor then heated to the desired temperature. In line with that, glycerol was also heated separately, until the desired temperature was reached. When the glycerol was fed into the reactor, this time was considered as the starting point of the reaction. The reaction ran for 6 hours. Samples were withdrawn every 30 minutes in the first 4 hours and then every one hour for the rest of time. Acid number of samples were analyzed by titration using $\mathrm{NaOH} 0.1 \mathrm{~N}$. The PFAD-glycerol esterification was also carried out for various mole ratios and catalyst loadings.

\subsection{Thin Layer Chromatography (TLC) Analysis}

The distribution of free fatty acid in PFAD and the distribution of reaction product were measured by TLC analysis. The free fatty acids in PFAD possibly consisted of linoleic acid, oleic acid, stearic acid, and palmitic acid [10]. PFAD, samples, and all standards were diluted with chloroform before analysis. Alumina TLC plate $(10 \times 20 \mathrm{~cm})$ was used and 5 samples $(10 \mu \mathrm{L}$ of each) were dropped and analysed in each plate. A mixture of hexane, ethyl ether, and methanol (80:20:2 of volume ratio) was used as mobile phase. Quantification was based on photo-densitometry scanning using CAMAG TLC Scanner 3. The spots representing fatty acid, mono-, di-, and tri-glyceride were determined based on retention factor (Rf) of each component standard.

\section{Results and Discussion}

\subsection{Thin Layer Chromatography of Free Fatty Acid Content in PFAD}

Chromatogram for all standards of fatty acids, mono-, di-, and tri-glycerides provided necessary retention factor for identifying components based on the peak formed in the chromatogram of samples. The result of TLC measurement for standards of fatty acid, mono-, di-, and tri-glycerides are shown in Table 1 . The photograph of photo-densitometry scanning was given in Appendix.

Table 1. Retention factor and peak area resulted from TLC scanning of standards.

\begin{tabular}{lccc}
\hline Chemical & Retention Factor & Peak Area, AU & Mass, $\boldsymbol{\mu g}$ \\
\hline Linoleic acid & $0.06-0.10$ & 458.3 & 133.3 \\
Oleic acid & $0.22-0.33$ & 1819.6 & 166.7 \\
Stearic acid & $0.58-0.86$ & 684.5 & 200.0 \\
Palmitic acid & $0.55-0.69$ & 1864.7 & 180.0 \\
Monolinolein & $0.08-0.12$ & 1300.7 & 414.9 \\
Monoolein & $0.12-0.19$ & 2504.4 & 3119.7 \\
Dilinolein & $0.35-0.45$ & 587.1 & 211.7 \\
Diolein & $0.51-0.55$ & 281.9 & 3.3 \\
Trilinolein & $0.81-0.87$ & 1001.3 & 344.4 \\
Triolein & $0.71-0.73$ & 113.5 & 39.0 \\
\hline
\end{tabular}

PFAD chromatogram is given in Fig. 2. It showed that there were 3 peaks formed. Based on the retention factor resulted from the standard measurement, the first and the second peak are linoleic acid and oleic acid, consecutively. It can be concluded that linoleic acid and oleic acid are the major components of free fatty acid composing PFAD. The third peak formed at Rf $0.43-0.50$ referred to dilinolein standard. 
Based on previous research by Thomas [11], retention factor between 0.35 and 0.55 also referred to diglyceride. Table 2 shows the measurement result of PFAD using TLC. Based on this quantitative TLC analysis, free fatty acid concentration in PFAD was 3.44 mgeq. $\mathrm{g}^{-1}$ (acid number 137.60). It was relatively the same with titration method using $\mathrm{NaOH} 0.1 \mathrm{~N}$ standard solution, which showed 3.38 mgeq. $^{-1}$ (acid number 135.22).

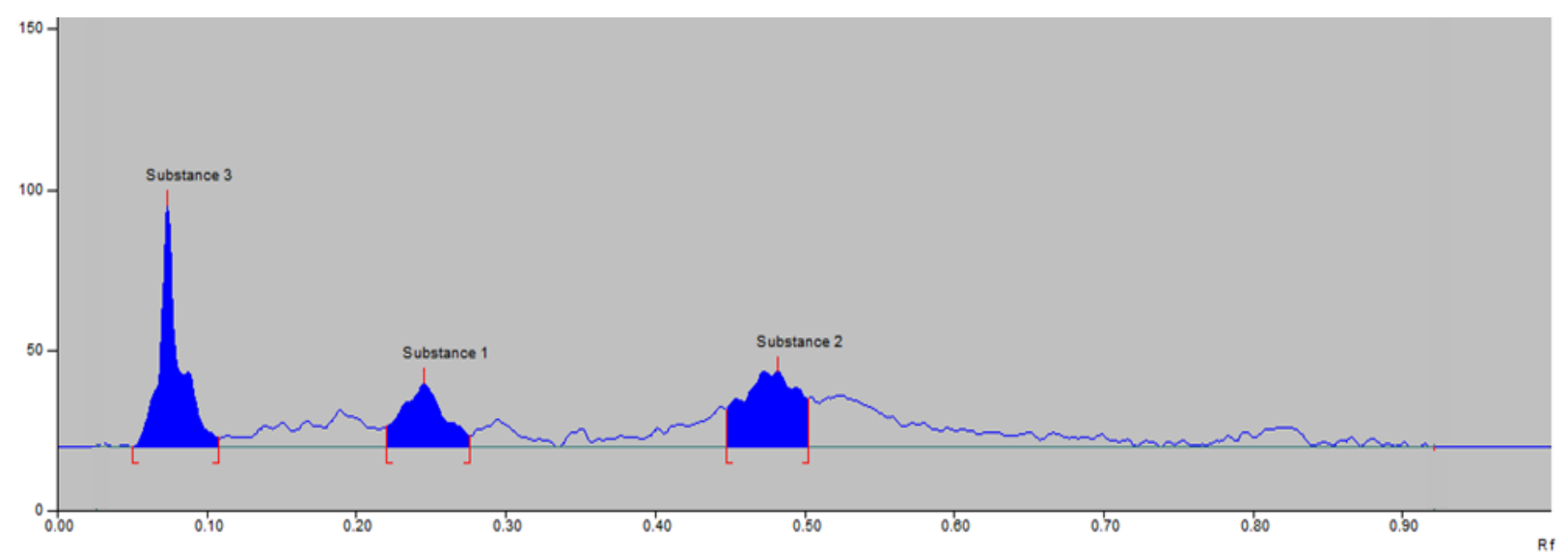

Fig. 2. Chromatogram resulted from TLC analysis of PFAD.

Table 2. Quantification of TLC measurement of PFAD sample in TLC plate.

\begin{tabular}{cccccc}
\hline Peak & Retention Factor (Rf) & $\begin{array}{c}\text { Identified } \\
\text { Chemical }\end{array}$ & Peak Area, AU & Mass, $\mu \mathrm{g}$ & Ci, mgeq/g \\
\hline 1 & $0.05-0.10$ & Linoleic acid & 828.9 & 241.15 & 2.94 \\
2 & $0.22-0.28$ & Oleic acid & 476 & 43.61 & 0.50 \\
3 & $0.43-0.50$ & Dilinolein & 894.4 & 10.53 & 0.06 \\
\hline
\end{tabular}

\subsection{The Effect of Reaction Temperature}

The proposed kinetic model has assumed that external mass transfer and intraparticle diffusion resistance could be neglected. The external mass transfer resistance could be eliminated as long as the stirrer speed is equal or greater than $400 \mathrm{rpm}$ [12]. The intraparticle diffusion resistance could also be neglected as long as the cation resin particle diameter is below $1.25 \mathrm{~mm}$ [12]. According to the manufacturer specification of Tulsion 42SM, the maximum particle diameter of cation resin was $1.08 \mathrm{~mm}$. In this research, the stirrer speed was set at about $450 \mathrm{rpm}$, slightly lower than previous research by [13]. To investigate the effect of temperature, the esterification reaction was carried out in $180-210^{\circ} \mathrm{C}$. The experimental result can be seen in Table 3.

Theoretical volume of water recovered at the end of reaction was estimated based on glycerol purity and PFAD conversion. Glycerol $155.3 \mathrm{~g}$ contains $38 \mathrm{~mL}$ of water. By assuming that the overall conversion was $100 \%$, the $144 \mathrm{~g}$ of PFAD would produce $9 \mathrm{~mL}$ of water so that the total water gained at the end of reaction will be about $47 \mathrm{~mL}$. Table 3 shows that the amount of water produced in the end of reaction was around $47 \mathrm{~mL}$. It meant that the reflux system worked well to remove water from reaction mixture. 
Table 3. Experimental data of acid number $\left(\mathrm{mg} \mathrm{NaOH} \cdot \mathrm{g}^{-1}\right)$ and fatty acid concentration (mgeq. $\left.\mathrm{g}^{-1}\right)$ for various reaction temperatures of PFAD-glycerol esterification

\begin{tabular}{cccccccccc}
\hline \multirow{2}{*}{ Time, hours } & \multicolumn{2}{c}{$\mathbf{1 8 0}^{\mathbf{}} \mathbf{C}$} & \multicolumn{2}{c}{$\mathbf{1 9 0}^{\mathbf{}} \mathbf{C}$} & \multicolumn{2}{c}{$\mathbf{2 0 0}^{\circ} \mathbf{C}$} & \multicolumn{2}{c}{$\mathbf{2 1 0}^{\circ} \mathbf{C}$} \\
\cline { 2 - 9 } & $\mathbf{A . N}$ & $\mathbf{C}$ & $\mathbf{A . N}$. & $\mathbf{C}$ & $\mathbf{A . N}$ & $\mathbf{C}$ & $\mathbf{A . N}$. & $\mathbf{C}$ \\
\hline 0.0 & 135.22 & 3.38 & 134.09 & 3.35 & 134.92 & 3.37 & 137.70 & 3.44 \\
0.5 & 100.86 & 2.52 & 66.76 & 1.67 & 59.32 & 1.48 & 53.14 & 1.33 \\
1.0 & 54.02 & 1.35 & 40.71 & 1.02 & 32.30 & 0.81 & 31.23 & 0.78 \\
1.5 & 38.41 & 0.96 & 28.67 & 0.72 & 19.68 & 0.49 & 20.58 & 0.51 \\
2.0 & 24.92 & 0.62 & 19.50 & 0.49 & 14.11 & 0.35 & 10.53 & 0.26 \\
2.5 & 22.47 & 0.56 & 18.39 & 0.46 & 7.71 & 0.19 & 5.49 & 0.14 \\
3.0 & 18.24 & 0.46 & 16.21 & 0.41 & 7.33 & 0.18 & 4.46 & 0.11 \\
3.5 & 17.65 & 0.44 & 12.25 & 0.31 & 7.07 & 0.18 & 4.17 & 0.10 \\
4.0 & 10.91 & 0.27 & 9.28 & 0.23 & 6.31 & 0.16 & 3.68 & 0.09 \\
5.0 & 8.62 & 0.22 & 7.94 & 0.20 & 4.52 & 0.11 & 3.28 & 0.08 \\
6.0 & 7.14 & 0.18 & 6.72 & 0.17 & 4.07 & 0.10 & 3.10 & 0.08 \\
\hline Water volume, $\mathrm{mL}$ & 47.00 & \multicolumn{4}{c}{47.10} & & 49.20 & 51.50 \\
\hline
\end{tabular}

Two models, Eley-Rideal and Langmuir-Hinshelwood, were examined by comparing the experimental data and simulation results, in which the Sum of Square of Errors (SSE) of experimental data was employed to consider its fitness. Both models did not fit the experimental data well in $180^{\circ} \mathrm{C}$ (see Fig. 3). But, there was a tendency that the Langmuir - Hinshelwood model gave satisfying result because of lower SSE value. Fatty acid molecular size (in this case linoleic acid) of about $9.9 \AA$ and glycerol molecular size of about $4.94 \AA$ were the reasons why LH model suited. Both fatty acid and glycerol molecules could get into the $200 \AA$ diameter of catalyst pore. Because of its polar functional group, both molecules can be adsorbed. The worry about inability of fatty acid molecule entering the pore of the catalyst due to its large molecular size was tackled by the study by Clowutimon [14]. The study proved that fatty acid molecule could be adsorbed well by adsorbent whose pore size $(57-85 \AA)$ was even smaller than the pore size of catalyst used in this work $(200 \AA)$. The SSE result can be seen in Table 4.

Table 4. Comparison of SSE result for esterification reaction in $180-210^{\circ} \mathrm{C}$.

\begin{tabular}{ccc}
\hline Temperature & Eley-Rideal & Langmuir Hinshelwood \\
\hline 180 & 0.2300 & 0.1833 \\
190 & 0.0271 & 0.0258 \\
200 & 0.0249 & 0.0241 \\
210 & 0.0168 & 0.0160 \\
\hline
\end{tabular}




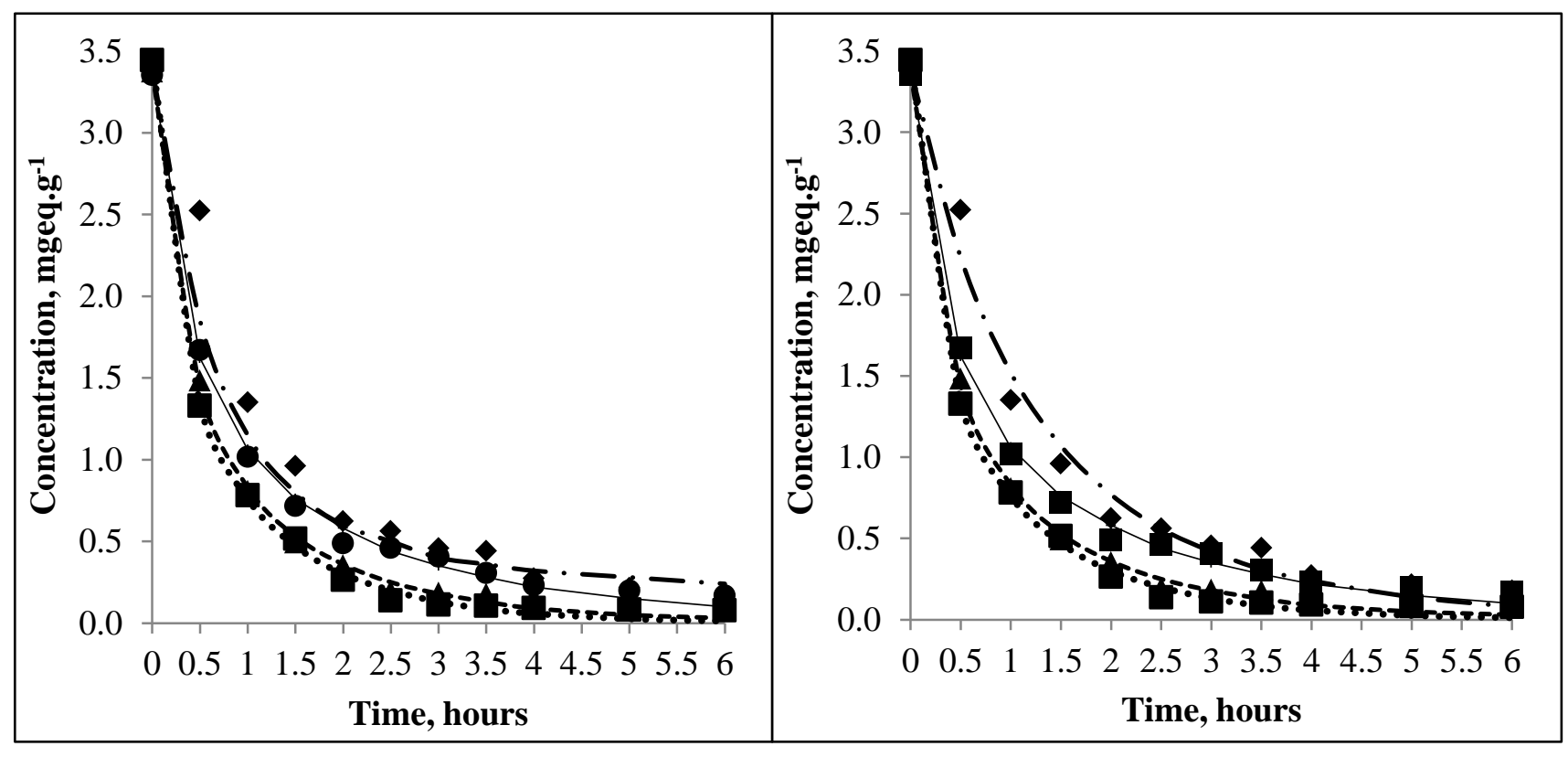

(a)

(b)

Fig. 3. Simulation result of (a) Eley-Rideal model and (b) Langmuir-Hinshelwood model with $\diamond: 180^{\circ} \mathrm{C}$ $\bullet: 190^{\circ} \mathrm{C} \boldsymbol{\Delta}: 200^{\circ} \mathrm{C} \mathbf{\square}: 210^{\circ} \mathrm{C}$.

Based on Arrhenius equation, temperature dependent formula for every reaction and equilibrium constant can be synthesized. The Arrhenius equation for constants of Langmuir - Hinshelwood model rate of reaction equation are given below. Almost all activation energy of reaction constants, symbolized by $\mathrm{E}$, is slightly lower or greater than 10,000 cal.mol-1. This simulation result stood in line with the assumption that surface reaction be rate-limiting.

$$
\begin{aligned}
& k r_{1}=2.10^{8} . \exp \left(-\frac{8,114.91}{R \cdot T}\right) \\
& k r_{2}=2 \cdot 10^{18} \cdot \exp \left(-\frac{18,651.97}{R . T}\right) \\
& k r_{3}=4 \cdot 10^{22} \cdot \exp \left(-\frac{22,864 \cdot 41}{R \cdot T}\right) \\
& K_{1}=54,975 \cdot \exp \left(-\frac{6,110.02}{R \cdot T}\right) \\
& K_{2}=641 . \exp \left(-\frac{2,722.19}{R . T}\right) \\
& K_{A}=3.10^{7} \cdot \exp \left(-\frac{7,002.19}{R \cdot T}\right) \\
& K_{9}=7 \cdot 10^{7} \cdot \exp \left(-\frac{7,222.74}{R \cdot T}\right)
\end{aligned}
$$




$$
\begin{aligned}
& K_{10}=2.10^{6} \cdot \exp \left(-\frac{6,078.23}{R \cdot T}\right) \\
& K_{11}=29,287 \cdot \exp \left(-\frac{5,247.67}{R \cdot T}\right)
\end{aligned}
$$

As the comparison to the simulation result of reaction and equilibrium constants, some values of activation energy reported by previous researches were taken. The selection is based on the experiment condition of this work. It is preferred that the catalyst is insoluble and there are parallel esterification reactions so that not only mono-ester formed but also di-ester and tri-ester formed. Reported values of activation energy from literatures indicated that the activation energy value gained in this work is acceptable and not over-estimated. Only for activation energy of monoglyceride formation reaction was the value much lower than the activation energy value in the literatures (see Table 5). The most possible explanation for this phenomenon is because there is reflux system in this work to remove water from the system so that the reaction could run irreversibly and the activation energy got lower. For the activation energy of diglyceride and tri-glyceride the value is closed with the value reported form literatures.

\begin{tabular}{|c|c|c|c|c|c|c|}
\hline Reference & $\begin{array}{c}\text { Carboxylic } \\
\text { Acid }\end{array}$ & $\begin{array}{c}\text { Alcoh } \\
\text { ol }\end{array}$ & $\begin{array}{c}\mathrm{T} \\
\left({ }^{\circ} \mathrm{C}\right)\end{array}$ & Catalyst & Kinetics & $\begin{array}{c}\text { Activation Energy, } \\
\text { cal.mol-1 }^{-1}\end{array}$ \\
\hline This work & $\begin{array}{l}\text { Linoleic } \\
\text { acid } \\
\text { Oleic acid }\end{array}$ & $\begin{array}{l}\text { Glycer } \\
\text { ol }\end{array}$ & $\begin{array}{c}180- \\
210\end{array}$ & $\begin{array}{l}\text { Tulsion } \\
42 \mathrm{SM}\end{array}$ & $\begin{array}{l}\text { Langmuir- } \\
\text { Hinshelwood }\end{array}$ & $\begin{aligned} E_{1} & =8,114.91 \\
E_{2} & =18,651.97 \\
E_{3} & =22,864.41\end{aligned}$ \\
\hline Lee et al. [9] & $\begin{array}{l}\text { Propionic } \\
\text { acid }\end{array}$ & $\begin{array}{c}\mathrm{n}- \\
\text { Butan } \\
\text { ol }\end{array}$ & $\begin{array}{l}80- \\
120\end{array}$ & Amberlyst 35 & $\begin{array}{l}\text { Langmuir- } \\
\text { Hinshelwood }\end{array}$ & $\mathrm{E}_{1}=15,292.8^{*}$ \\
\hline $\begin{array}{l}\text { Rattanaphra } \\
\text { [15] }\end{array}$ & $\begin{array}{l}\text { Myristic } \\
\text { acid }\end{array}$ & $\begin{array}{c}\text { Metha } \\
\text { nol }\end{array}$ & $\begin{array}{c}120- \\
170\end{array}$ & $\begin{array}{l}\text { Sulfated } \\
\text { zirconia }\end{array}$ & $\begin{array}{c}\text { Pseudo- } \\
\text { homogeneous }\end{array}$ & $\mathrm{E}_{1}=5,402.4^{*}$ \\
\hline $\begin{array}{l}\text { Orjuela et al. } \\
\text { [13] }\end{array}$ & $\begin{array}{l}\text { Succinic } \\
\text { acid }\end{array}$ & $\begin{array}{c}\text { Ethan } \\
\text { ol }\end{array}$ & $\begin{array}{l}70- \\
100\end{array}$ & Amberlyst 70 & $\begin{array}{c}\text { Pseudo- } \\
\text { homogeneous }\end{array}$ & $\begin{array}{l}E_{1}=16,248^{*} \\
E_{2}=15,120^{*}\end{array}$ \\
\hline $\begin{array}{l}\text { Kulawska } \\
{[16]}\end{array}$ & $\begin{array}{c}\text { Maleic } \\
\text { anhydride }\end{array}$ & $\begin{array}{c}\text { Octan } \\
\text { ol }\end{array}$ & $\begin{array}{c}130- \\
160 \\
\end{array}$ & $\begin{array}{c}\text { Dowex } \\
50 \mathrm{~W} 8-100 \\
\end{array}$ & Power Law & $\mathrm{E}_{1}=15,840^{*}$ \\
\hline $\begin{array}{l}\text { Tsai et al. } \\
{[17]}\end{array}$ & $\begin{array}{l}\text { Glutaric } \\
\text { acid }\end{array}$ & $\begin{array}{c}\text { Metha } \\
\text { nol }\end{array}$ & $\begin{array}{c}40- \\
60\end{array}$ & Amberlyst 35 & $\begin{array}{c}\text { Quasi - } \\
\text { homogeneous }\end{array}$ & $\begin{array}{l}E_{1}=8,777.37^{*} \\
E_{2}=4,057.45^{*}\end{array}$ \\
\hline $\begin{array}{l}\text { Cardoso et } \\
\text { al. [18] }\end{array}$ & Oleic acid & $\begin{array}{c}\text { Ethan } \\
\text { ol }\end{array}$ & $\begin{array}{l}35- \\
75\end{array}$ & $\mathrm{SnCl}_{2}$ & Power Law & $\mathrm{E}_{1}=11,205.6^{*}$ \\
\hline
\end{tabular}

Table 5. Activation energy values reported in the literature for esterification reactions.

*Adopted from literature by converting the original value into similar unit of activation energy in this work (cal.mol $\left.{ }^{-1}\right)$

The optimum reaction temperature would be related to the monoglyceride selectivity. The slight difference of experimental data between $200^{\circ} \mathrm{C}$ and $210^{\circ} \mathrm{C}$ esterification reaction showed that these two temperatures were optimum condition. On Fig. 4 below, the predictions were calculated based on the constants value gained from previous simulation. Monoglyceride concentration along the time was higher in $200^{\circ} \mathrm{C}$ than that of $210^{\circ} \mathrm{C}$. 


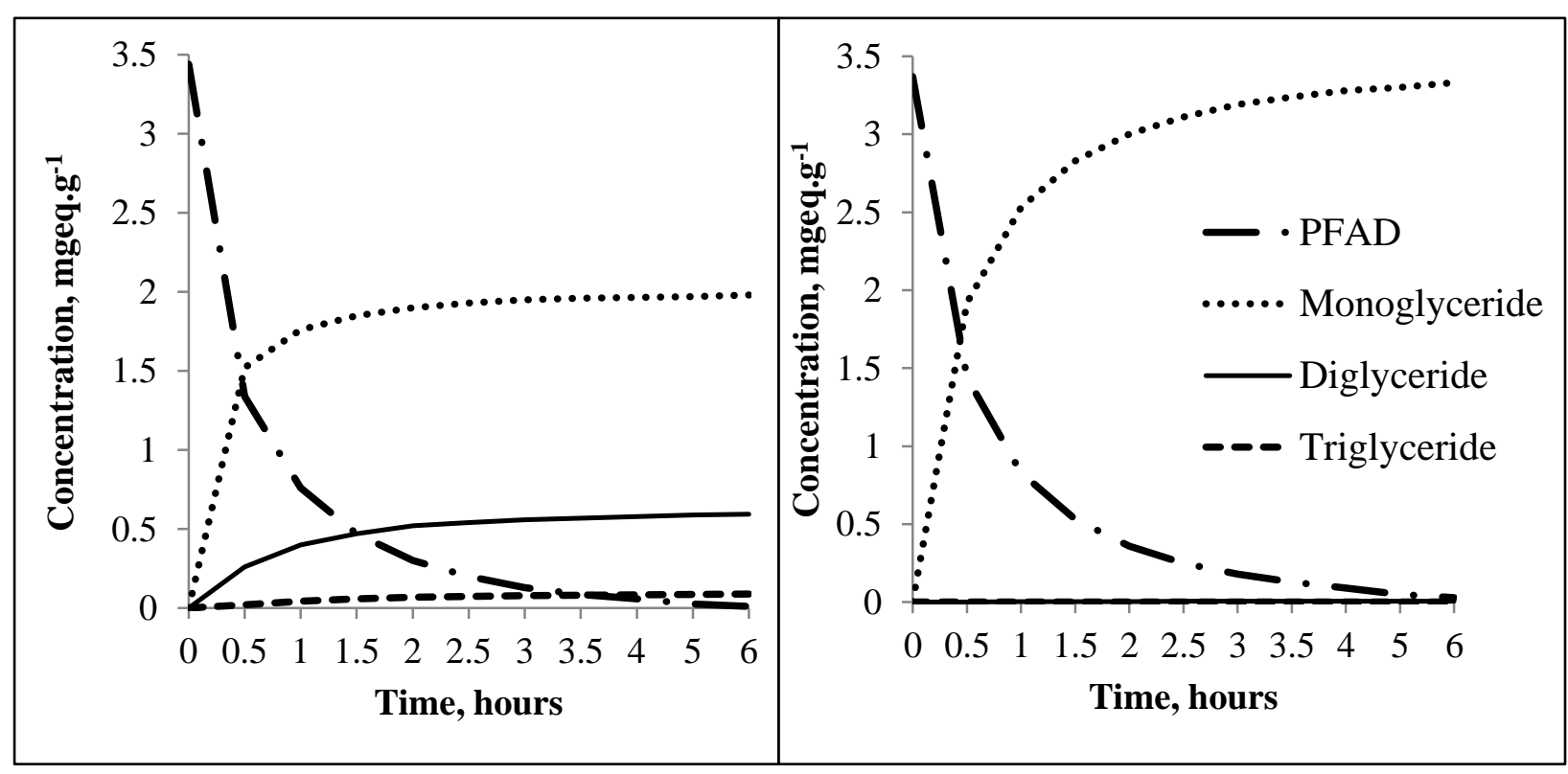

(a)

(b)

Fig. 4. Comparison of mono-, di-, and tri-glyceride rate of production at a). $210^{\circ} \mathrm{C}$ and b). $200^{\circ} \mathrm{C}$ reaction temperature.

\subsection{Glycerol-PFAD Mole Ratio Effect}

Previous experiment was undergone with glycerol-PFAD mole ratio of 3:1. Fewer number of glycerol will reduce the raw material cost so that the experiment tried to vary the mole ratio in reducing the mole of glycerol. The mole ratios during the experiment were 1:3, 1:1, and 2:1, and the reaction ran at temperature of $200^{\circ} \mathrm{C}$. For mole ratio variation, Langmuir-Hinshelwood model was chosen because of its ability to fit the experimental data in various reaction temperatures. Mole ratio of 1:1, 2:1, and 3:1 (see Table 6) permitted the assumption of ignoring the mass transfer resistance. All reaction and equilibrium constants value closed to the calculation result of $200^{\circ} \mathrm{C}$ esterification reaction. It could be concluded that mole ratio of reactants did not influence the reaction rate constants.

Different phenomenon was encountered at the 1:3 mole ratio of reactant. The reaction rate constant value of $\mathrm{kr}_{1}$ is certainly less than those of 1:1 to 3:1. This could be caused by the mass transfer resistance in the liquid phase. At the mole ratio of glycerol:PFAD to be 1:3, the mass ratio of glycerol:PFAD is 1:8 so that PFAD dominates the liquid mixture. During the reaction, there were many small explosions emerging from the reaction mixture, which indicated that the reaction mixture was very viscous. Hence, mass transfer resistance controlled the overall rate of reaction at 1:3 mole ratio of glycerol:PFAD.

Acid number declined faster for greater alcohol-fatty acid mole ratio [19]. Experiment result showed the same trend. The greatest acid number reductions happened on 2:1 and 3:1 of glycerol-PFAD mole ratio. The optimum mole ratio was chosen based on the $k_{1} \cdot\left(k_{2}+k_{3}\right)^{-1}$, showing the selectivity of monoglyceride production [20]. For 1:1 and 2:1, $k_{1} \cdot\left(k_{2}+k_{3}\right)^{-1}$ value were 217.4 and 243.1 while $3: 1$ showed greater value, 243.5. Therefore, the optimum mole ratio was still 3:1 to increase the monoglyceride production. 
Table 6. Reaction and equilibrium constants for various glycerol-PFAD mole ratios in $200^{\circ} \mathrm{C}$ esterification reaction.

\begin{tabular}{ccccc}
\hline Constants & $\mathbf{1 : 3}$ & $\mathbf{1 : 1}$ & $\mathbf{2 : \mathbf { 1 }}$ & $\mathbf{3 : \mathbf { 1 }}$ \\
\hline$k r_{1}$ & 0.1113 & 0.2391 & 0.2431 & 0.2435 \\
$k r_{2}$ & 0.0210 & 0.0007 & 0.0007 & 0.0007 \\
$k r_{3}$ & 0.014 & 0.0004 & 0.0003 & 0.0003 \\
$K_{1}$ & 0.1244 & 0.1043 & 0.1044 & 0.1044 \\
$K_{2}$ & 0.8137 & 0.8136 & 0.8137 & 0.8129 \\
$K_{A}$ & 0.3544 & 0.3444 & 0.3544 & 0.3532 \\
$K_{9}$ & 0.8431 & 0.8331 & 0.8431 & 0.8433 \\
$K_{10}$ & 0.3600 & 0.3601 & 0.3600 & 0.3613 \\
$K_{11}$ & 0.5129 & 0.5139 & 0.5129 & 0.5137 \\
\hline $\mathrm{SSE}$ & 0.5775 & 0.5305 & 0.1170 & 0.0241 \\
\hline
\end{tabular}

\subsection{Catalyst Loading Effect}

The ability of catalyst to create a new reaction pathway and increase the reaction rate asserted its function in the reaction. Unfortunately, catalyst consumption must be limited in order to reduce the production cost [21]. In this experiment, the catalyst loading was varied with $0,5 \% \mathrm{wt}$ interval. The experiment for catalyst loading variation used $2 \%, 2.5 \%$, and $3 \%$ wt of catalyst loading.

Reaction constants for main reaction and side reactions (shown in Table 7) had a positive trend for the increasing of catalyst loading. Theoretically, this result was true, because the increase of catalyst loading would enlarge the value of $\mathrm{kr}_{1}, \mathrm{kr}_{2}$, and $\mathrm{kr}_{3}$. Total active site $(C t)$ as a result of catalyst addition is the reason. In every reaction constant, $C t$ has a second order in case of Langmuir-Hinshelwood model [22, 23]. The more catalyst are used, the more active sites to be accessed for undergoing the esterification reaction.

Table 7. Catalyst loading effect to the reaction and equilibrium constants.

\begin{tabular}{cccc}
\hline Constants & $\mathbf{2}$ \%wt & $\mathbf{2 . 5}$ \%wt & $\mathbf{3} \% \mathbf{w t}$ \\
\hline$k r_{1}$ & 0.0795 & 0.1345 & 0.2435 \\
$k r_{2}$ & 0.0005 & 0.0007 & 0.0007 \\
$k r_{3}$ & 0.0001 & 0.002 & 0.0003 \\
$K_{1}$ & 0.1528 & 0.1505 & 0.1044 \\
$K_{2}$ & 0.8412 & 0.8002 & 0.8129 \\
$K_{A}$ & 0.3351 & 0.3592 & 0.3532 \\
$K_{9}$ & 0.8369 & 0.8436 & 0.8433 \\
$K_{10}$ & 0.3648 & 0.3623 & 0.3613 \\
$K_{11}$ & 0.5138 & 0.5134 & 0.5137 \\
\hline SSE & 0.0884 & 0.0637 & 0.0241 \\
\hline
\end{tabular}

\subsection{Thin Layer Chromatography Analysis of Reaction Product}

The chosen samples to be analysed were the reaction product at both $200^{\circ} \mathrm{C}$ and $210^{\circ} \mathrm{C}$ reaction temperature. Both samples were taken at the 2.5 hours reaction time. Reaction time greater than 2.5 hours did not show significant decrease of acid number. Quantitative analysis was conducted after the TLC plate was scanned by TLC scanner. Identification of what chemical related to certain peak of certain retention factor (Rf) followed the TLC analysis result of standards shown in Table 1.

Chromatogram in Fig. 5 shows that there are five peaks formed from every reaction product sample. The first peak belongs to linoleic acid because of its retention factor. Linoleic acid remained in the reaction 
product sample because the conversion had not reached 100\% conversion. At this point, acid number measured by alkalimetric method was compared with acid number derived from TLC analysis. Acid number measured using alkalimetric method at the reaction time of 2.5 hours was between $5-8(0.14-0.2$ mgeq. $\mathrm{g}^{-1}$ ), while acid number measured using TLC analysis resulted in $9.87 \mathrm{mg} \mathrm{NaOH} . \mathrm{g}^{-1}$ for $200^{\circ} \mathrm{C}$ sample and $3.30 \mathrm{mg} \mathrm{NaOH} \cdot \mathrm{g}^{-1}$ for $210^{\circ} \mathrm{C}$ sample of remaining linoleic acid. Both alkalimetric and TLC analysis method showed closed results. Thus, it was acceptable to select alkalimetric method as primary method in synthesizing the reaction kinetics.

More specifically, according to TLC analysis result, the chemicals distribution presented inside the reaction product mixture was consistent with the TLC analysis result of PFAD as reactant. In PFAD, the number of oleic acid was much fewer than linoleic acid. As the consequence, it could be seen on Table 8 and Table 9 that no oleic acid presented as the remaining reactant after 2.5 hours esterification. It could be said that oleic acid was totally consumed during the esterification. This phenomenon was reasonable due to the much lower number of oleic acid than linoleic acid. Also, quantitative verification showed that the initial concentration of oleic acid in PFAD was $0.50 \mathrm{mgeq} / \mathrm{g}$ (see Table 2) and the measurable monoolein concentration by TLC was $0.36 \mathrm{mgeq} / \mathrm{g}$ (see Table 8) and $0.40 \mathrm{mgeq} / \mathrm{g}$ (see Table 9). Based on mole balance concept, the concentration of oleic acid should be the same as monoolein by assuming that the mass inside the reactor was constant. Therefore, the measurement could still be accepted because the deviation was not too far away and it was still capable of proving that all oleic acid was converted.

Beside fatty acid, there was also dilinolein in PFAD (see Table 2). Dilinolein was identified as the "impurity" for fatty acid components inside PFAD. By the time the esterification reaction went on, the probability of those dilinolein to react with fatty acid to form trilinolein existed. It was proved by the presence of trilinolein on TLC analysis result of the solution of reaction product ( $\mathrm{Rf} 0.81-0.85)$ which had been confirmed in Table 1 that peak with Rf $0.81-0.87$ was trilinolein. The absence of triolein in the reaction product was caused by few number of oleic acid so that the pathway to form diolein as the precursor of triolein formation was blocked.

The presence of dilinolein and trilinolein on reaction product, apart from connate dilinolein inside PFAD, was also supported by the excessive number of linoleic acid in PFAD. According to the study by Mostafa [8], excessive number of carboxylic acid group could stimulate the side reaction of diglyceride and triglyceride formation to occur. Thus, it was so normal that diglyceride and triglyceride formed were coming from linoleic acid and not oleic acid.

To verify the selectivity discussed in sub-section 3.2, the measurement result of reaction product mixture using TLC was compared to the simulation result. According to the simulation result using suitable reaction mechanism, monoglyceride formed in $200^{\circ} \mathrm{C}$ reaction temperature was greater than that of $210^{\circ} \mathrm{C}$. Apparently, this stood in line with the TLC analysis result of which could be seen in Table 8 and Table 9 . The peak area of monoglyceride from $200^{\circ} \mathrm{C}$ sample was greater than that of $210^{\circ} \mathrm{C}$ sample and the concentration of which was too. Diglyceride and triglyceride formed in both temperatures were just slightly different in number. From this quantitative analysis, it could be concluded that $200^{\circ} \mathrm{C}$ was the optimum temperature. Therefore, the simulation result, using only acid number in MATLAB processing to determine the concentration of mono-, di-, and tri-glyceride formed, matched with the experimental data and provided the same conclusion.

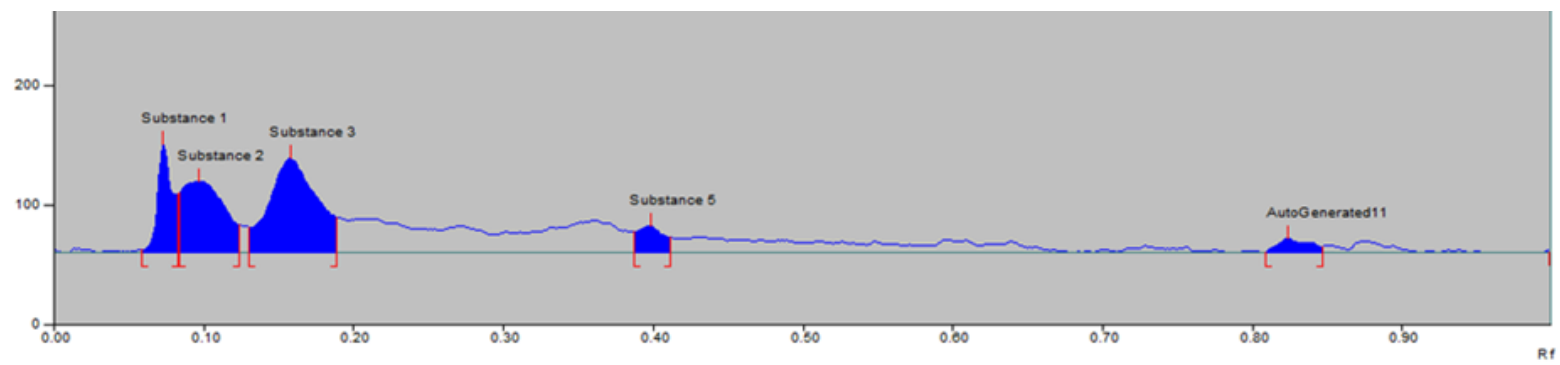

(a) 


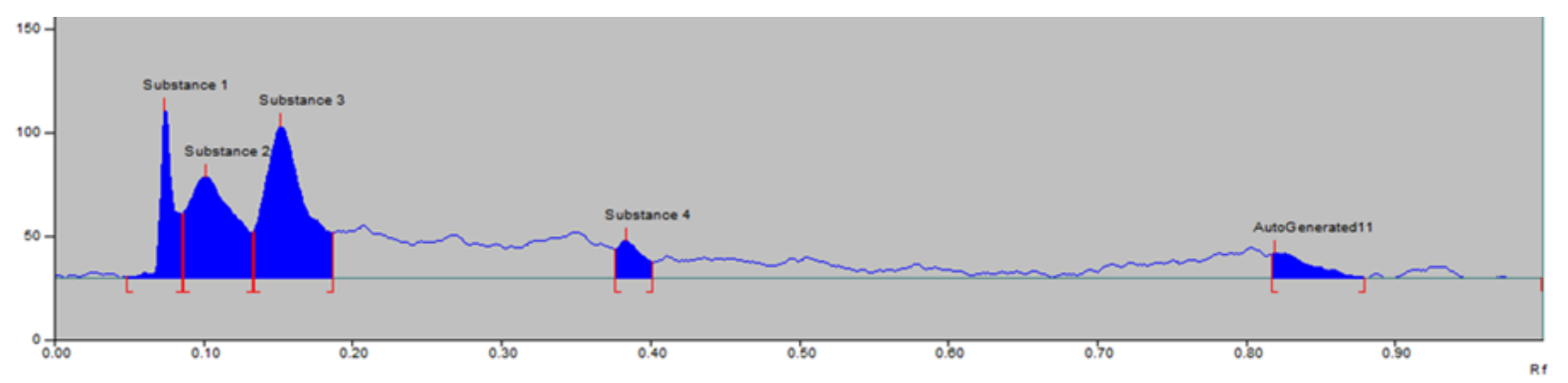

(b)

Fig. 5. Chromatogram resulted from TLC plate containing reaction product sample at reaction time 2.5 hours with reaction temperature of: a). $200^{\circ} \mathrm{C}$; b). $210^{\circ} \mathrm{C}$.

Table 8. Identification of chemical compound detected in chromatogram from $200^{\circ} \mathrm{C}$ sample.

\begin{tabular}{cccccc}
\hline Peak & Rf & Peak Area, AU & Mass, $\boldsymbol{\mu g}$ & $\begin{array}{l}\text { Identified } \\
\text { Chemical }\end{array}$ & $\mathbf{C}_{\mathbf{i}}, \mathbf{m g e q} / \mathbf{g}$ \\
\hline 1 & $0.06-0.08$ & 822.8 & 239.37 & Linoleic acid & 0.22 \\
2 & $0.08-0.12$ & 1568.3 & 500.27 & Monoolein & 0.36 \\
3 & $0.13-0.19$ & 2329.1 & 2901.30 & Monolinolein & 2.13 \\
4 & $0.39-0.41$ & 360.6 & 130.02 & Dilinolein & 0.05 \\
5 & $0.81-0.85$ & 230.6 & 79.31 & Trilinolein & 0.02 \\
\hline
\end{tabular}

Table 9. Identification of chemical compound detected in chromatogram from $210^{\circ} \mathrm{C}$ sample.

\begin{tabular}{cccccc}
\hline Peak & Rf & Peak Area, AU & Mass, $\boldsymbol{\mu g}$ & $\begin{array}{c}\text { Identified } \\
\text { Chemical }\end{array}$ & $\mathbf{C}_{\mathbf{i}}, \mathbf{m g e q} / \mathbf{g}$ \\
\hline 1 & $0.05-0.09$ & 642.6 & 186.95 & Linoleic acid & 0.27 \\
2 & $0.09-0.13$ & 1382.5 & 441.00 & Monoolein & 0.40 \\
3 & $0.13-0.19$ & 1336.7 & 1665.09 & Monolinolein & 1.88 \\
4 & $0.38-0.40$ & 282.6 & 101.90 & Dilinolein & 0.05 \\
5 & $0.82-0.88$ & 295.3 & 101.56 & Trilinolein & 0.04 \\
\hline
\end{tabular}

\section{Conclusions}

The esterification reaction of PFAD-glycerol using strong acidic cation exchanger needed high reaction temperature. However, high temperature reaction using xylene reflux system ensures that the reaction ran irreversibly. The reflux system worked well in removing all water from reaction mixture in temperature range of $180-210^{\circ} \mathrm{C}$. Langmuir-Hinshelwood kinetic model suited with the experimental data with lower SSE value for every reaction temperature than Eley-Rideal model did. The optimum reaction temperature was $200^{\circ} \mathrm{C}$ to produce high conversion of PFAD and high selectivity of monoglyceride production. The optimum condition to achieve high conversion of PFAD and high monoglyceride production selectivity is 3:1 for glycerol-PFAD mole ratio and 3\% wt for catalyst loading. The kinetic model described here can be used to predict the compositions of esterification product.

\section{Acknowledgement}

The authors are grateful for the financial support of General Directorate of High Education of Indonesia through Competency Research Grant. The authors are also grateful for the material support of PT. Alkindo Mitraraya (glycerol and PFAD) and PT. Pupuk Sriwijaya (Tulsion 42SM cation exchanger). 


\begin{tabular}{|c|c|c|}
\hline \multicolumn{3}{|c|}{ Nomenclature: } \\
\hline \multicolumn{3}{|c|}{ Symbols } \\
\hline$k r_{1}$ & {$\left[\mathrm{~g} \cdot \mathrm{mgeq}^{-1} \cdot \mathrm{minute}^{-1}\right]$} & reaction rate constant of monoglyceride formation \\
\hline & {$\left[\mathrm{g} \cdot \mathrm{mgeq}^{-1} \cdot \mathrm{minute}^{-1}\right]$} & reaction rate constant of diglyceride formation \\
\hline$k r_{3}$ & [g.mgeq ${ }^{-1} \cdot$ minute $\left.^{-1}\right]$ & reaction rate constant of triglyceride formation \\
\hline$K_{i}$ & [g.mgeq ${ }^{-1}$ ] & adsorption or desorption equilibrium constant of component $i$ \\
\hline$C_{i}$ & [mgeq. $\left.\mathrm{g}^{-1}\right]$ & concentration of component $i$ \\
\hline A.N. & {$\left[\mathrm{mg} \mathrm{NaOH} \cdot \mathrm{g}^{-1}\right]$} & acid number \\
\hline & {$\left[\mathrm{mgeq} \cdot \mathrm{g}^{-1} \cdot\right.$ minute $\left.^{-1}\right]$} & rate of formation equation for component $i$ \\
\hline Rf & & retention factor \\
\hline$R$ & {$\left[1.987 \mathrm{cal}^{\mathrm{mol}} \mathrm{mol}^{-1} \cdot \mathrm{K}^{-1}\right]$} & ideal gas constant \\
\hline$E_{1}$ & {$\left[\mathrm{cal} . \mathrm{mol}^{-1}\right]$} & activation energy of mono-ester formation reaction \\
\hline$E_{2}$ & {$\left[\mathrm{cal} . \mathrm{mol}^{-1}\right]$} & activation energy of di-ester formation reaction \\
\hline$E_{3}$ & {$\left[\mathrm{cal} . \mathrm{mol}^{-1}\right]$} & activation energy of tri-ester formation reaction \\
\hline \multicolumn{3}{|c|}{ Subscripts } \\
\hline G & & glycerol \\
\hline $\mathrm{P}$ & & palm fatty acid distillate \\
\hline M & & monoglyceride \\
\hline $\mathrm{D}$ & & diglyceride \\
\hline $\mathrm{T}$ & & triglyceride \\
\hline A & & water \\
\hline S & & active site \\
\hline \multicolumn{3}{|c|}{ Abbreviations } \\
\hline SSE & & Sum of Square of Error \\
\hline PFAD & & Palm Fatty Acid Distillate \\
\hline $\mathrm{CPO}$ & & Crude Palm Oil \\
\hline TLC & & Thin Layer Chromatography \\
\hline
\end{tabular}

\section{References}

[1] B. S. Chu, S. Y. Quek, and B. S. Baharin, "Optimization of enzymatic hydrolysis for concentration of vitamin E in palm fatty acid distillate," Food Chem., vol. 80, pp. 295 - 302, 2003.

[2] S. Zullaikah, C. C. Lai, S. R. Vali, and Y. H. Ju, "A two-step acid-catalyzed process for the production of biodiesel from rice bran oil," Bioresource Technol., vol. 96, pp. 1889 - 1896, 2005.

[3] M. Di Serio, R. Tesser, L. Pengmei, and E. Santacesaria, "Heterogeneous catalysts for biodiesel production," Energ. Fuel, vol. 22, pp. 207-217, 2008.

[4] P. K. T. Oldring and G. Hayward, "Alkyd resins," in Resins for Surface Coatings, 1st ed. London: SITA Technology, 1987, ch. IV, pp. 127-133.

[5] Z. Mufrodi, R. Rochmadi, S. Sutijan, and A. Budiman, "Synthesis acetylation of glycerol using batch reactor and continuous reactive distillation column", Engineering Journal, vol. 18, no. 2, pp. 29-39, 2014.

[6] S. H. Ali and S. Q. Merchant, "Kinetic study of Dowex 50 WX8-catalyzed esterification and hydrolysis of benzyl acetate," Ind. Eng. Chem. Res., vol. 48, pp. 2519-2532, 2009.

[7] M. R. Altiokka, E. Akbay, and Z. Him, "Impregnation of 12-Tungstophosphoric acid on tonsil: An effective catalyst for esterification of formic acid with n-butyl alcohol and kinetic modelling," J. Mol. Catal. A-Chem., vol. 385, pp. 18-25, 2014.

[8] N. A. Mostafa, A. Maher, and A. Abdelmoez, "Production of mono-, di-, and triglycerides from waste fatty acid through esterification with glycerol," ABB: Advances in Bioscience and Biotechnology, vol. 4 pp. 900-907, 2013.

[9] M. J. Lee, J. Y. Chiu, and H. Lin, "Kinetics of catalytic esterification of propionic acid and n-butanol over Amberlyst 35," Ind. Eng. Chem. Res., vol. 41, pp. 2882-2887, 2002. 
[10] B. T. Y. Ping and M. Yusof, "Characteristics and properties of fatty acid distillate from palm oil," Oil Palm Bulletin, vol. 59, pp. 5-11, 2009.

[11] A. E. Thomas, J. E. Scharoun, and H. Ralston, "Quantitative estimation of isomeric monoglycerides by thin-layer chromatography," J. Amer. Oil Chem., vol. 42, pp. 789 - 792, 1965.

[12] M. E. Bambase, N. Nakamura, J. Tanaka, and M. Matsumura, "Kinetics of hydroxidecatalyzed methanolysis of crude sunflower oil for the production of fuel-grade methyl esters," J. Chem. Technol. Biot., vol. 82, pp. 273-280, 2007.

[13] A. Orjuela, A. J. Yanez, A. Santhanakrishnan, C. T. Lira, and C. T. Miller, "Kinetics of mixed succinic acid/acetic acid esterification with Amberlyst 70 ion exchange resin as catalyst," Chem. Eng. J., vol. 188, pp. $98-107,2012$.

[14] W. Clowutimon, P. Kitchaiya, and P. Assawasaengrat, "Adsorption of free fatty acid from crude palm oil on magnesium silicate derived from rice husk," Engineering Journal, vol. 15, no. 3, pp. 15 - 25, 2011.

[15] D. Rattanaphra, A. P. Harvey, A. Thanapimmetha, and P. Srinophakun, "Kinetic of myristic acid esterification with methanol in the presence of triglycerides over sulfated zirconia," Renew. Energ., vol. 36, pp. 2679-2686, 2011.

[16] M. Kulawska, J. Z. Sadowski, and J. Skrzypek, "Kinetics of the esterification of maleic anhydride with octyl, decyl or dodecyl alcohol over dowex catalyst," React. Kinet. Catal. Lett, vol. 85, pp. 51-56, 2005.

[17] Y. T. Tsai, H. M. Lin, and M. J. Lee, "Kinetics of heterogeneous esterification of glutaric acid with methanol over Amberlyst 35," J. Taiwan Inst. Chem. E., vol. 42, pp. 271-277, 2014.

[18] A. L. Cardoso, S. C. G. Neves, and M. J. da Silva, "Esterification of oleic acid for biodiesel production catalyzed by $\mathrm{SnCl}_{2}$ : A kinetic investigation," Energies, vol. 1, pp. 79-92, 2008.

[19] J. R. Kastner, J. Miller, D. P. Geller, and J. Locklin, "Catalytic esterification of fatty acids using solid acid catalyst generated from biochar and activated carbon," Catal. Today, vol. 190, pp. 122 - 132, 2012.

[20] H. Sudibyo, "Esterification of palm fatty acid distillate - Glycerol over cation resin catalyst," M. Eng. thesis, Chemical Engineering Dept., Gadjah Mada Univ., Yogyakarta, 2015.

[21] L. A. S. do Nascimento, R. S. Angelica, C. E. F. da Costa, J. R. Zamian, and G. N. R. Filho, "Comparative study between catalysts for esterification prepared from kaolins," Appl. Clay Sci., vol. 51, no. 3, pp. 267-273, 2011.

[22] M. Bruzzone and A. Carbonaro, "Influence of catalysts on the production cost of some polyolefins and polydiolefins, with reference to new catalysts based on 4 and $5 \mathrm{f}$ group of elements of the periodic table," Inorg. Chim. Acta, vol. 94, no. 6, pp. 291-295, 1984.

[23] H. S. Fogler, "Catalysis and catalytic reactor," in Elements of Chemical Reaction Engineering, $3^{\text {rd }}$ ed. New Delhi: Prentice Hall, 2004, ch. X, pp. 591-603. 


\section{Appendix-TLC Analysis Result Of Standard Solutions}

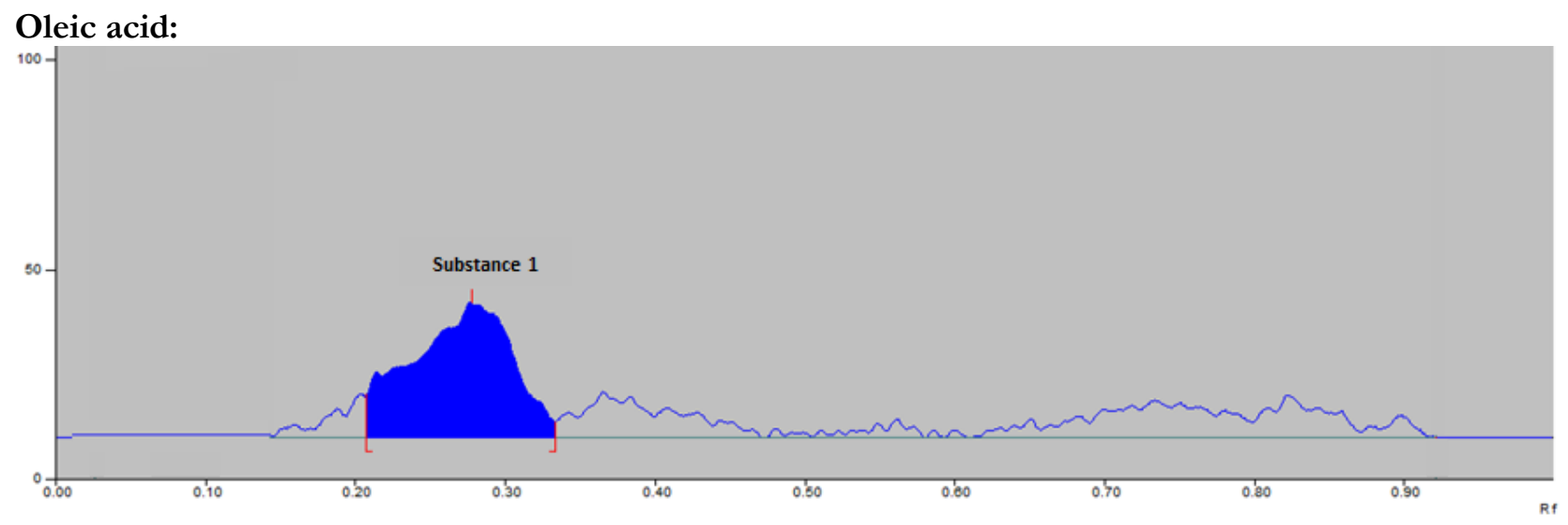

\section{Linoleic acid:}

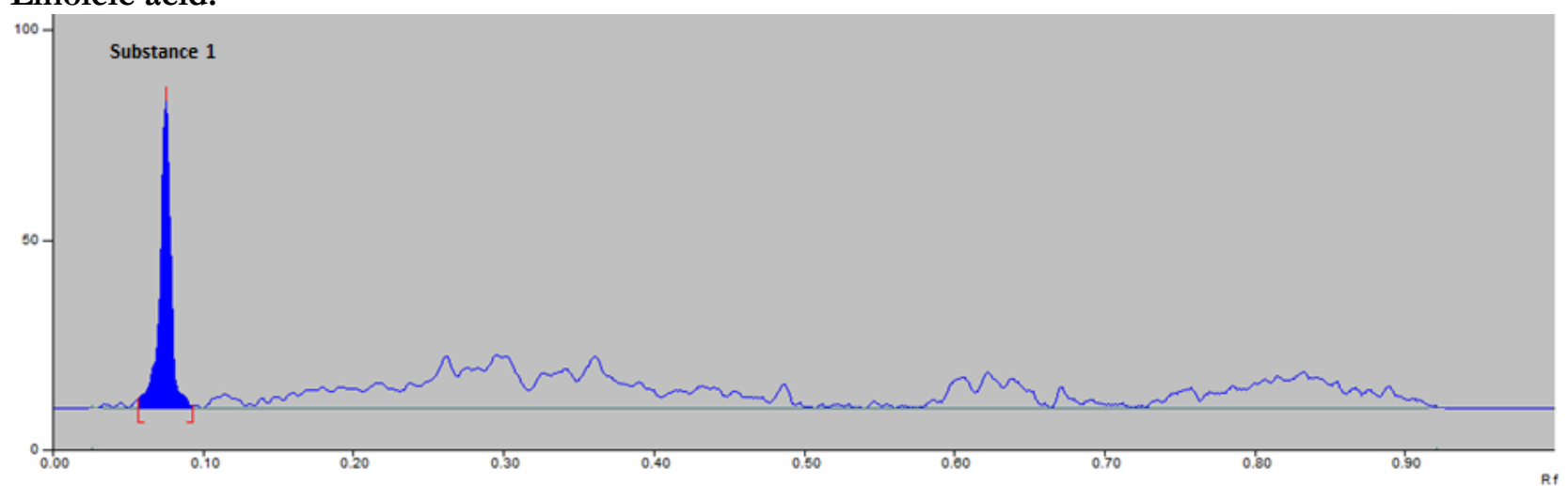

Stearic acid:

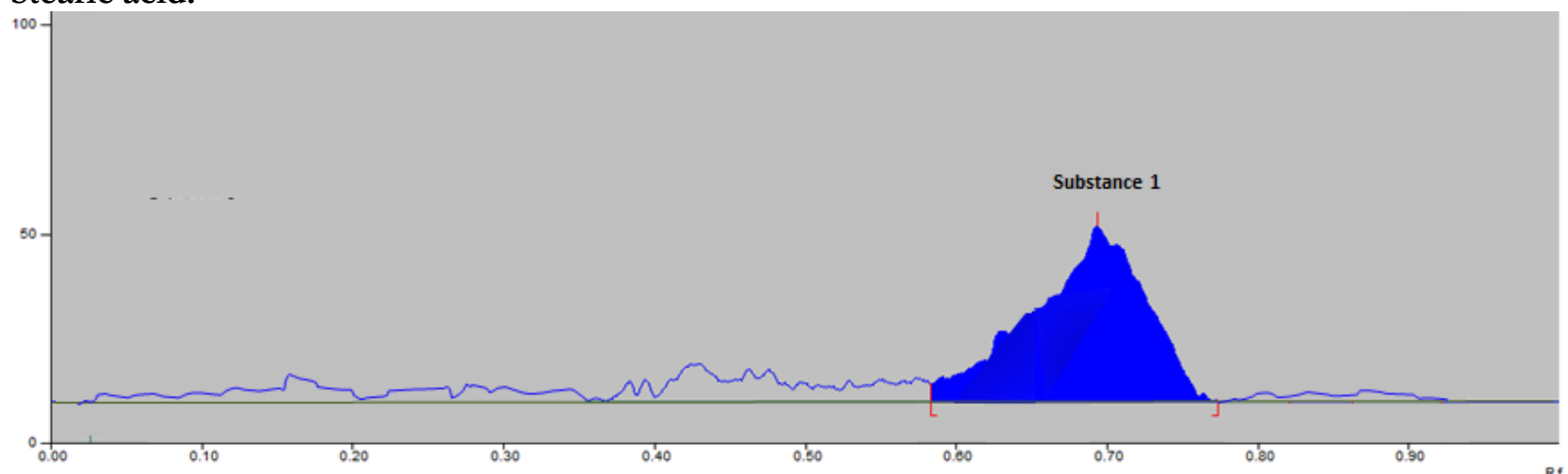




\section{Palmitic acid:}

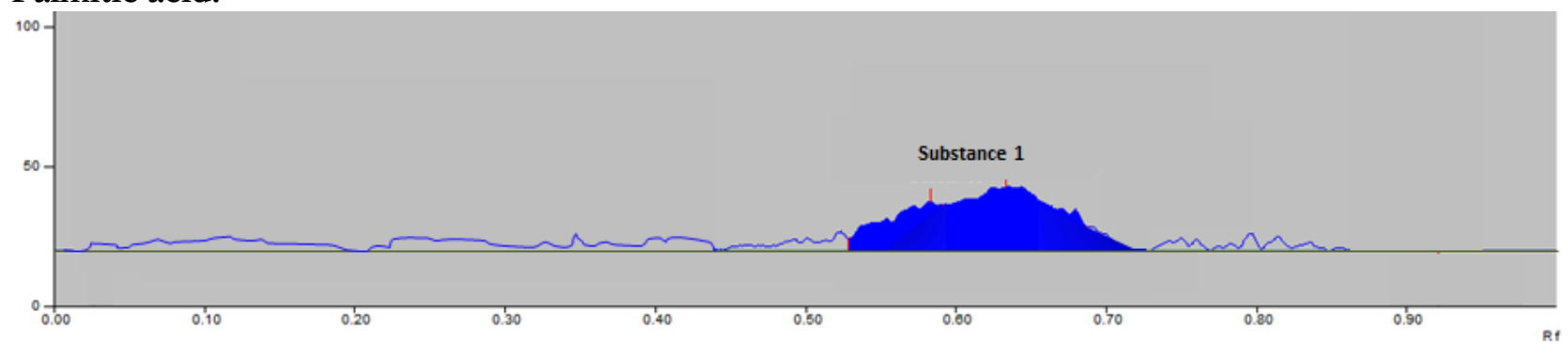

\section{Monoolein:}

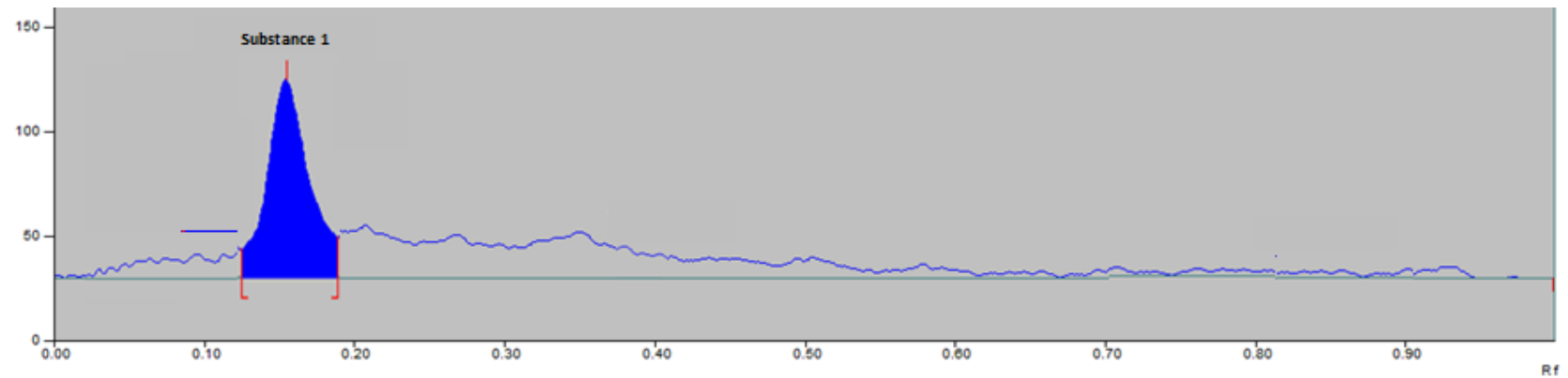

\section{Monolinolein:}

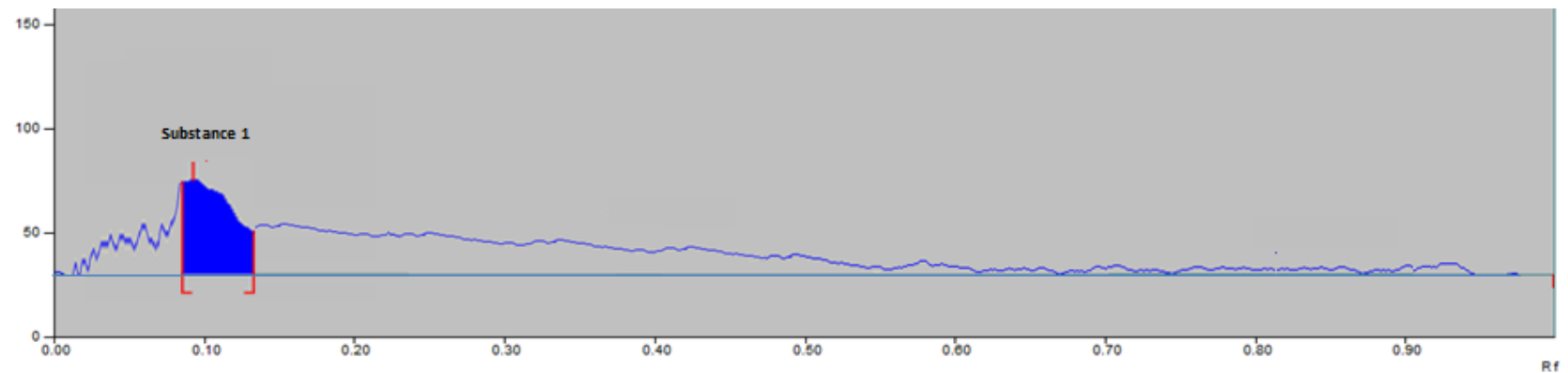

\section{Diolein:}

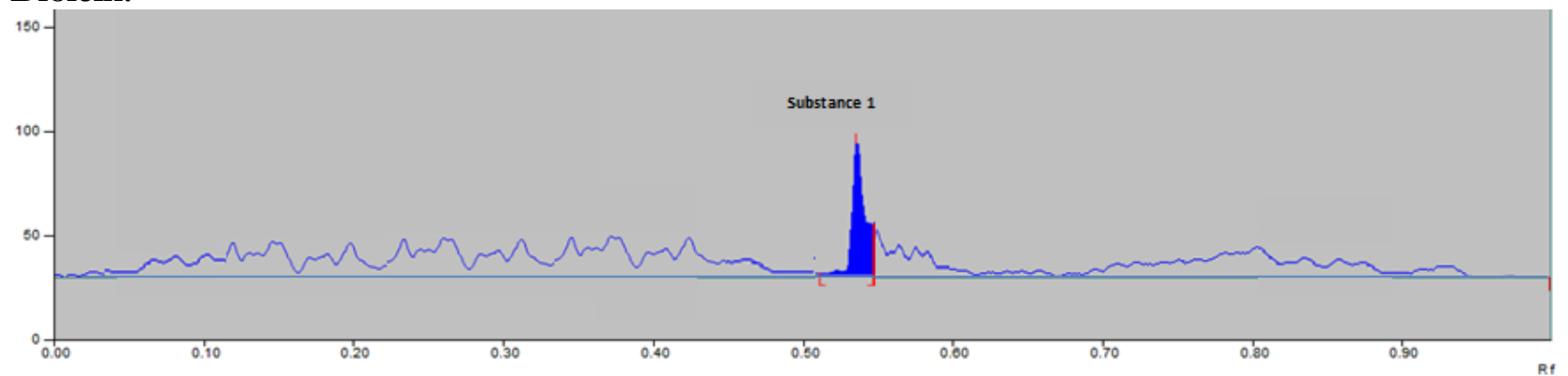




\section{Dilinolein:}

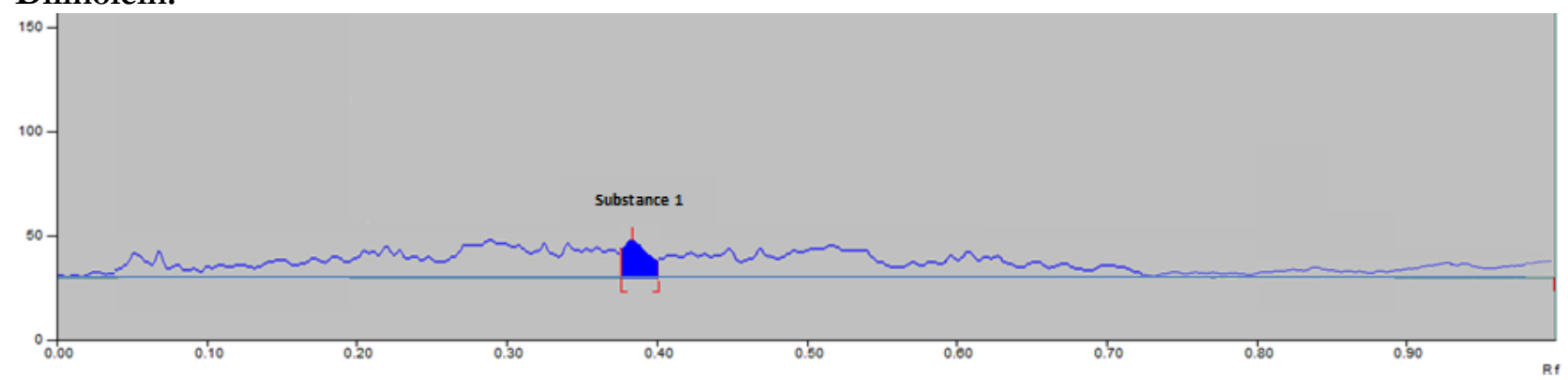

\section{Triolein:}

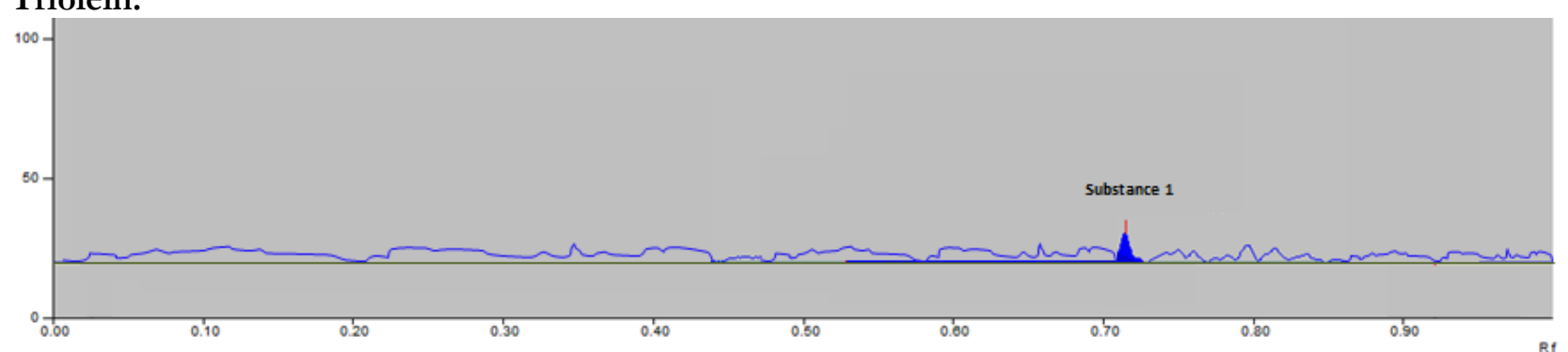

\section{Trilinolein:}

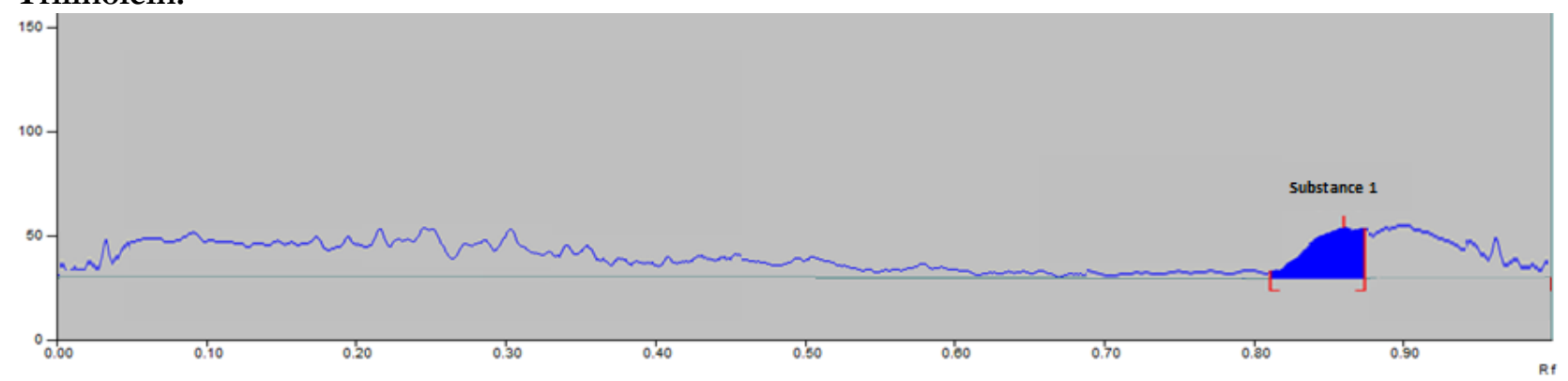

